\title{
Correlação entre absorção de água e tempo de cozimento de cultivares de feijão
}

\author{
Correlation among water soaking and cooking time of bean cultivars \\ Josana de Abreu Rodrigues ${ }^{1}$ Nerinéia Dalfollo Ribeiro ${ }^{2}$ \\ Patrícia Medianeira Grigoletto Londero ${ }^{1}$ Alberto Cargnelutti Filho ${ }^{3}$ \\ Danton Camacho Garcia ${ }^{2}$
}

RESUMO

\begin{abstract}
O objetivo deste trabalho foi analisar o comportamento de cultivares de feijão quanto aos testes da capacidade de absorção da água pelos grãos e do tempo de cozimento, bem como avaliar correlações entre essas características visando à identificação precoce de linhagens de fácil cozimento. Foi adotado o delineamento experimental inteiramente casualizado, arranjado em fatorial $2 \times 9$, com três repetições. As cultivares utilizadas foram TPS Nobre e Pérola e os grãos foram imersos em água destilada durante 2 a 18 horas. Os resultados obtidos evidenciaram que a capacidade de absorção da água pelos grãos aumentou com o tempo em que permaneceram embebidos, até atingir o máximo de hidratação: $13 \mathrm{~h} 7 \mathrm{~min}$ e $13 \mathrm{~h} 12 \mathrm{~min}$ para as cultivares TPS Nobre e Pérola, respectivamente. O tempo de cozimento diminuiu à medida que os grãos permaneceram imersos até 12h49min, para as duas cultivares. A capacidade de absorção da água pelos grãos e o tempo de cozimento apresentaram correlação negativa e significativa.
\end{abstract}

Palavras-chave: Phaseolus vulgaris L., qualidade de grão para cozimento, metodologias.

\section{ABSTRACT}

The purpose of this work was to evaluate the behavior of bean cultivars regarding water soaking test and cooking time as well as the possible correlation of these variables to identify bean lines with high cooking capacity. A factorial of two cultivars (TPS Nobre and Pérola) and different times (2 to 18 hours of soaking) in a completely randomized design, with three replications, was conducted. Soaking capacity was increased over time up to 13h07min for TPS Nobre and 13h12min for Pérola cultivar. Cooking time was reduced after 12h49min of soaking for both cultivars. There was a high and negative correlation between water soaking and cooking time.

Key words: Phaseolus vulgaris L., cooking grain quality, cooking method.

\section{INTRODUÇÃO}

O tempo de cozimento é fator fundamental para a aceitação de uma cultivar de feijão pelos consumidores, pois a disponibilidade para o preparo das refeições é, muitas vezes, restrita (COSTA et al., 2001). Cultivares que apresentam grãos com cozimento rápido proporcionam economia de tempo e de energia (YOKOYAMA\& STONE, 2000). Além disso, períodos prolongados de cozimento causam mudanças estruturais em nível celular, provocando perda de nutrientes (WASSIMI et al., 1988).

A identificação de linhagens com menor tempo de cozimento, rápida capacidade de hidratação, com tegumentos que não se partam durante o cozimento e com alta expansão volumétrica, após o

\footnotetext{
${ }^{1}$ Aluno do Programa de Pós-graduação em Agronomia, Universidade Federal de Santa Maria (UFSM), Bolsista do Conselho Nacional de Desenvolvimento Científico e Tecnológico e da Coordenação de Aperfeiçoamento de Pessoal de Nível Superior. ${ }^{2}$ Professor, Doutor, Departamento de Fitotecnia, Centro de Ciências Rurais, UFSM, 97105-900, Santa Maria, RS. E-mail: neiadr@smail.ufsm.br (Autor para correspondência).

${ }^{3}$ Pesquisador, Doutor, Fundação Estadual de Pesquisa Agropecuária, Rua Gonçalves Dias, 570, 90130-060, Porto Alegre, RS. Email: alberto-cargnelutti@fepagro.rs.gov.br.
} 
cozimento, é desejável (CARBONELL et al., 2003). A avaliação do tempo de cozimento é exigida para a inscrição de nova cultivar de feijão junto ao Serviço Nacional de Proteção de Cultivares, do Ministério da Agricultura e Produção Agropecuária (BRASIL, 2001). A metodologia oficial requer a utilização do cozedor de Mattson que consiste no cozimento de 25 grãos sob cada pino do aparelho (PROCTOR \& WATTS, 1987). Essa metodologia, apesar de eficiente, avalia pequeno número de amostras além do que a demora para obtenção da informação do tempo de cozimento torna-a inexeqüível para um grande número de populações, comum no caso de gerações precoces.

O desenvolvimento de metodologias que possibilitem a identificação precoce de linhagens com menor tempo de cozimento tornam-se indispensáveis. A capacidade de absorção da água pelos grãos, antes do cozimento, tem sido utilizada, visto que a capacidade de cocção está relacionada à rápida absorção(GARCIA-VELA\& STANLEY, 1989; PHLAK et al., 1989). A avaliação desse teste é de fácil mensuração, rápida e permite o descarte de linhagens indesejáveis mesmo nas primeiras gerações segregantes (RAMALHO et al., 1993; COSTA et al., 2001). Correlação positiva entre a capacidade de absorção da água pelos grãos e o tempo de cozimento foi relatada em genótipos desenvolvidos nos programas de melhoramento do Brasil (SCHOLZ \& FONSECA JÚNIOR, 1999a; SCHOLZ \& FONSECA JÚNIOR, 1999b; DALLACORTE et al., 2003). Por outro lado, a utilização do teste da capacidade de absorção da água pelos grãos, como indicativo do tempo de cozimento, tem sido questionada devido à baixa correlação encontrada (CARBONELL et al., 2003).

O tempo de embebição dos grãos de feijão para a avaliação da capacidade de absorção da água, sugerido pela metodologia oficial adotada é de 18 horas, e utiliza a relação de uma parte de grão para quatro partes de água, em temperatura ambiente (GARCIA-VELA \& STANLEY, 1989). Entretanto, há indicativo de que o tempo de permanência dos grãos em embebição possa ser reduzido para 4 horas (COSTA et al., 2001), ainda que trabalhos recentes utilizem 16 horas como critério (CARBONELL et al., 2003; DALLA CORTE et al., 2003). Esses resultados sugerem a necessidade de padronização do tempo de embebição dos grãos de feijão, em água destilada, haja vista que o tempo máximo de hidratação varia com o genótipo, podendo oscilar de $8 \mathrm{~h} 10 \mathrm{~min}$ (IAC Carioca Aruã) a 12h01min (IAC Carioca Pyatã) como relatado por RAMOS JÚNIOR \& LEMOS (2002).

Considerando estas informações, o objetivo do trabalho foi analisar o comportamento de duas cultivares de feijão quanto aos testes da capacidade de absorção de água pelos grãos e do tempo de cozimento, bem como avaliar a correlação entre essas características, para a identificação precoce de linhagens com facilidade de cozimento.

\section{MATERIAL E MÉTODOS}

Os experimentos foram conduzidos no Departamento de Fitotecnia, da Universidade Federal de Santa Maria (UFSM), Santa Maria - RS, utilizando grãos provenientes do Programa de Melhoramento de Feijão desta instituição.

O solo foi preparado de forma convencional e a adubação realizada no sulco de semeadura, de acordo com a interpretação da análise química do solo. A densidade da semeadura foi ajustada conforme recomendação da CEPEF (2001), para cultivares de hábitos de crescimento do tipo II e III. A adubação nitrogenada em cobertura foi parcelada em duas aplicações de $40 \mathrm{~kg} \mathrm{ha}^{-1}$ de nitrogênio nos estádios vegetativos de primeira (V3) e de terceira (V4) folhas trifoliadas. Os tratos culturais, como controle de insetos e de plantas invasoras, foram realizados, sempre que necessário, de maneira que a cultura não sofresse competição. A colheita manual e a trilha das plantas foram realizadas em janeiro de 2003 e, após a separação das impurezas, em máquinas de ar e peneira. Os grãos foram secos em terreiro de cimento, e, havendo necessidade, em estufa, até umidade de $12 \%$, em média. Em seguida, amostras de 2,0kg de grãos foram acondicionadas em sacos de papel e armazenadas em câmara fria $\left(0^{\circ} \mathrm{C}\right.$ de temperatura e $80 \%$ de umidade relativa) por sete meses, antes de realizar as análises. Esse período simula o tempo máximo em que, normalmente, os grãos são armazenados antes da comercialização.

$\mathrm{O}$ estudo foi realizado em delineamento experimental inteiramente casualizado, arranjado em fatorial $2 \times 9$ (duas cultivares e nove tempos de embebição), com três repetições de $50 \mathrm{~g}$ de grãos. As duas cultivares utilizadas foram TPS Nobre (preto) e Pérola (carioca), que apresentam hábito de crescimento indeterminado, com ramificações fechadas (tipo II) e com ramificações abertas (tipo III), respectivamente. Para o teste da capacidade de absorção da água, $50 \mathrm{~g}$ de grãos de feijão foram colocados em copos plásticos com $200 \mathrm{ml}$ de água destilada, em nove diferentes tempos de embebição ( 2 a 18 horas), à temperatura ambiente $\left( \pm 20^{\circ} \mathrm{C}\right)$. A cada 30 minutos, uma amostra de grãos foi colocada em embebição para compor os tratamentos, e a temperatura da água, antes do cozimento, foi monitorada. 
Após o tempo de embebição, os grãos foram retirados e parcialmente secos em papel toalha. A capacidade de absorção da água pelos grãos foi determinada pela diferença de peso antes e após a embebição (GARCIA-VELA \& STANLEY, 1989; PLHAK et al., 1989). A avaliação do volume de água absorvido pelos grãos foi realizada pelo uso da relação: volume absorvido $=[($ volume inicial - volume final $) /$ volume inicial $x$ 100]. A percentagem de grãos normais (com absorção normal de água) e a percentagem de grãos duros (sem a capacidade de hidratação) em relação ao número total de grãos avaliados foram quantificadas.

A avaliação do cozimento dos grãos foi realizada com o uso do aparelho cozedor de Mattson, com 25 pinos (PROCTOR \& WATTS, 1987). As amostras de grãos foram previamente embebidas em água destilada, nos tempos previstos, à temperatura ambiente $\left( \pm 20^{\circ} \mathrm{C}\right)$. A seguir, a água foi eliminada e os grãos colocados na placa suporte do aparelho ficando, cada pino, acima de um grão. $\mathrm{O}$ aparelho foi colocado em uma panela com água destilada fervente, mantendose o aquecimento. À medida que ocorria o cozimento, os pinos caíam e atravessavam os grãos, anotando-se o tempo decorrido do instante em que o cozedor foi colocado na água fervente até a queda do pino, e obtendo-se o tempo de queda de cada pino ou o tempo de cozimento de cada grão. O tempo necessário para que 13 pinos (metade +1 ) caíssem foi utilizado para calcular o tempo médio de cozimento de cada amostra.

Os dados obtidos foram submetidos à análise da variância, utilizando o teste de $\mathrm{F}$ em nível de $5 \%$ de probabilidade de erro, para testar as hipóteses dos efeitos principais e da interação. Também realizou-se a análise de correlação de Pearson entre as variáveis.

\section{RESULTADOS E DISCUSSÃO}

A análise de variância indicou interação significativa entre cultivares em função dos tempos de embebição para capacidade de absorção da água pelos grãos, volume de água absorvido, percentagem de grãos normais e percentagem de grãos duros, sugerindo resposta diferenciada das cultivares de feijão em função do tempo de permanência dos grãos em embebição. Entretanto, para o tempo de cozimento apenas os efeitos principais (cultivares e tempo de embebição) mostrando comportamento semelhante para as duas cultivares, quando imersas em água destilada sob diferentes tempos, foram significativos (Tabela 1).

Os coeficientes de variação (CV\%) obtidos para as variáveis consideradas no teste da capacidade de absorção da água pelos grãos (percentagem de absorção, volume de água absorvido e percentagem de grãos normais) foram baixos, sugerindo que maior precisão experimental pode ser obtida neste teste, quando comparado ao tempo de cozimento. No entanto, a percentagem de grãos duros apresentou elevado CV\% devido, provavelmente, à inexistência de grãos sem hidratação, mesmo nos menores períodos de embebição.

A capacidade de absorção da água pelos grãos aumentou com o tempo em que esses permaneceram embebidos, atingindo a máxima hidratação as $13 \mathrm{~h} 07 \mathrm{~min}$ e as $13 \mathrm{~h} 12 \mathrm{~min}$, para as cultivares TPS Nobre e Pérola, respectivamente (Figura 1). Resultados semelhantes haviam sido obtidos para a 'TPS Nobre', a qual apresentou tempo de $12 \mathrm{~h} 57 \mathrm{~min}$ (RAMOS JUNIOR et al., 2002). Já em feijões do grupo carioca, o tempo de completa hidratação dos grãos variou de $8 \mathrm{~h} 10 \mathrm{~min}$ a $12 \mathrm{~h} 01 \mathrm{~min}$, de acordo com o genótipo, sendo considerado um intervalo de tempo satisfatório pois simula o hábito da dona-de-casa em deixar o feijão de molho na noite anterior ao preparo da refeição (RAMOS JUNIOR \& LEMOS, 2002). Esses resultados sugerem que há necessidade de padronizar o tempo ideal de permanência dos grãos em embebição para a avaliação da capacidade de absorção da água, pois variabilidade genética tem sido observada para essa característica em germoplasma (SCHOLZ \& FONSECA JÚNIOR, 1999a; SCHOLZ \& FONSECA JÚNIOR, 1999b; COSTA et al., 2001; RAMOS JUNIOR et al., 2002; RAMOS JUNIOR \& LEMOS, 2002; CARBONELLet al., 2003; DALLACORTE et al., 2003; RIBEIRO et al., 2003).

O volume de água absorvido pelos grãos aumentou até 14h40min e 13h57min de imersão em água destilada, para as cultivares TPS Nobre e Pérola, respectivamente (Figura 1). Já a percentagem de grãos normais aumentou até alcançar 12h37min (TPS Nobre) e 13h01min (Pérola), pontos máximos de eficiência técnica (Figura 2). Os resultados obtidos sugerem que tempo superior a 13 horas de imersão dos grãos pode não ter eficiência na discriminação de diferenças no teste da capacidade de absorção da água pelos grãos, pois ocorre estabilização da percentagem de grãos normais e da capacidade de absorção da água.

Com relação à percentagem de grãos duros, ocorreu percentual reduzido de grãos sem a capacidade de hidratação (média geral $=3,74 \%$ ) para as duas cultivares, o que é aspecto favorável, indicando esforços da seleção contra essa característica no desenvolvimento das novas cultivares de feijão.

O tempo de cozimento diminuiu com o aumento do tempo de permanência dos grãos em 
Tabela 1 - Graus de liberdade (GL) e quadrado médio para capacidade de absorção da água pelos grãos (absorção), volume de água absorvido (volume), percentagem de grãos normais (normais), percentagem de grãos duros (duros) e tempo de cozimento em minutos (cocção) para as causas de variação, média e coeficiente de variação (CV). Santa Maria - RS, UFSM, 2003.

\begin{tabular}{|c|c|c|c|c|c|c|}
\hline \multirow{2}{*}{ Causas de variação } & \multirow{2}{*}{ GL } & \multicolumn{5}{|c|}{ Quadrado médio } \\
\hline & & absorção (\%) & volume (\%) & normais (\%) & duros $(\%)$ & cocção (min) \\
\hline Cultivar (C) & 1 & $54,622^{*}$ & $1145,770^{*}$ & $69,814^{*}$ & $69,837 *$ & $42,164^{*}$ \\
\hline Tempo (T) & 8 & $1602,175^{*}$ & $190,759 *$ & $284,947 *$ & $284,952 *$ & $146,859^{*}$ \\
\hline $\mathrm{C}^{*} \mathrm{~T}$ & 8 & $39,051^{*}$ & $5,548 *$ & $11,858 *$ & $11,858^{*}$ & $4,655^{\mathrm{ns}}$ \\
\hline Erro & 36 & 3,536 & 0,699 & 2,659 & 2,659 & 9,418 \\
\hline Média & - & 89,56 & 31,11 & 96,26 & 3,74 & 25,20 \\
\hline $\mathrm{CV}(\%)$ & - & 2,10 & 2,69 & 1,69 & 43,59 & 12,18 \\
\hline
\end{tabular}

$*=$ efeito significativo em nível de $5 \%$ de probabilidade de erro pelo teste $\mathrm{F} ;{ }^{\text {ns }}=$ efeito não significativo pelo teste $\mathrm{F}$.

embebição até as 12h49min (Figura 2). Esse resultado sugere que o período de imersão de 16 horas, para a permanência dos grãos de feijão em embebição antes da avaliação do tempo de cozimento pode ser desnecessário já que não possibilita cozimento mais rápido (PROCTOR \& WATTS, 1989; CARNEIRO et al., 1999a; CARNEIRO et al., 1999b; CARBONELLL et al., 2003; DALLA CORTE et al., 2003).

É sabido que o tempo de cozimento pode ser influenciado pelas condições de cultivo, pelo processo de beneficiamento e de armazenamento dos grãos (SCHOLZ \& FONSECA JÚNIOR, 1999b). Além disso, variabilidade genética para tempo de cozimento em feijão tem sido relatada variando de 22,1min a 100,3min (CARNEIRO et al., 1999a; CARNEIRO et al., 1999b; SCHOLZ \& FONSECA JÚNIOR, 1999a; SCHOLZ \& FONSECA JÚNIOR, 1999b; RAMOS JUNIOR et al., 2002; RAMOS JUNIOR \& LEMOS, 2002; CARBONELLLet al., 2003; DALLACORTEet al., 2003). Como estimativas de herdabilidade superiores a $60 \%$ foram encontradas em diferentes famílias de feijão, espera-se facilidades para a seleção dessa característica (BELICUAS et al., 2001).

As variáveis - capacidade de absorção da água pelos grãos e tempo de cozimento - apresentaram correlação negativa e significativa $(\mathrm{p}=0,01)$, para as

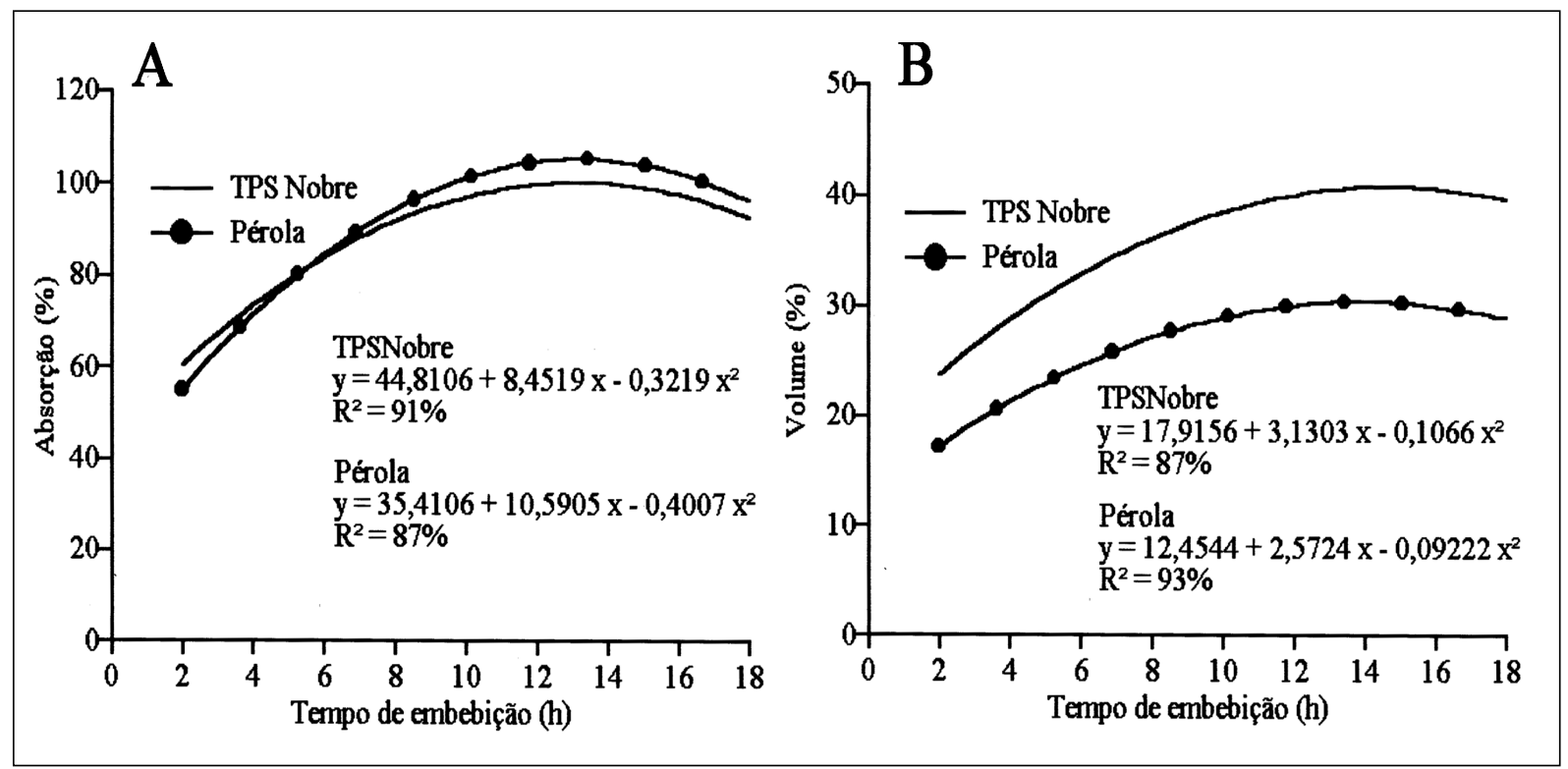

Figura 1 - Capacidade de absorção da água (A) e volume de água absorvida (B) por duas cultivares de feijão em função do tempo de embebição dos grãos, em água destilada. Santa Maria, RS, UFSM, 2003.

Ciência Rural, v.35, n.1, jan-fev, 2005. 


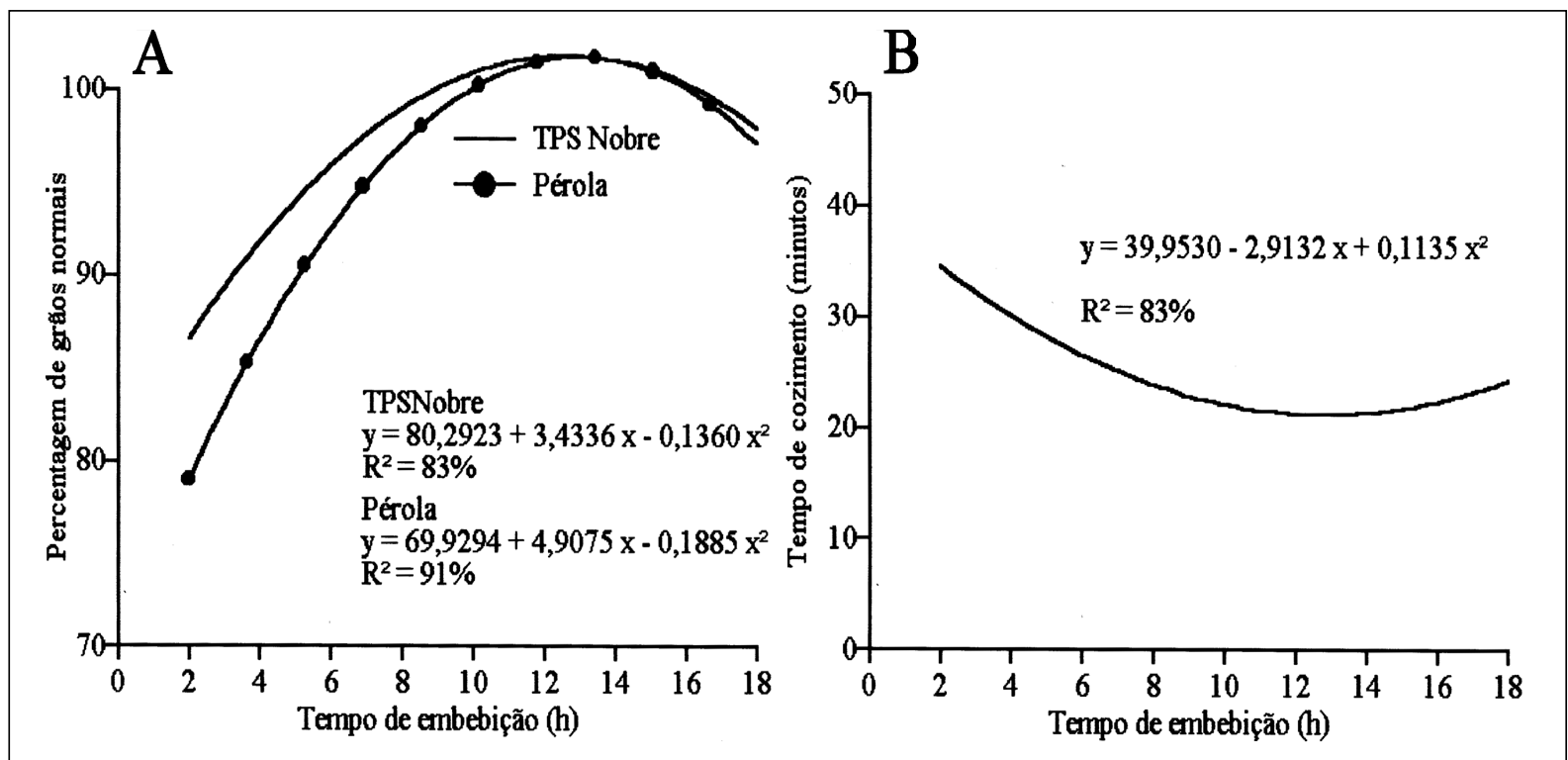

Figura 2 - Percentagem de grãos normais (A) e tempo de cozimento (B) por duas cultivares de feijão em função do tempo de embebição dos grãos, em água destilada. Santa Maria - RS, UFSM, 2003.

duas cultivares, mostrando que, à medida que ocorria o incremento na percentagem de absorção de água, reduzia-se o tempo de cozimento (Tabela 2). Esse resultado contraria aquele obtido por DALLA CORTE et al. (2003) que encontraram correlação positiva e alta, e com CARBONELL et al. (2003) que obtiveram valores de baixa-média magnitude entre as variáveis capacidade de absorção da água e tempo de cozimento. Provavelmente, as respostas diferenciadas obtidas sejam possíveis em decorrência de diferenças genéticas entre os genótipos e quanto ao tempo de embebição dos grãos, em água destilada.
Correlação positiva e significativa foi observada entre a capacidade de absorção da água pelos grãos e a percentagem de grãos normais, para as cultivares TPS Nobre $(0,9625)$ e Pérola $(0,9812)$ (Tabela 2). A alta associação entre essas duas características possibilita a utilização da percentagem de grãos normais (grãos com absorção normal de água), o que parece mais fácil e rápido do que a quantificação da absorção da água, já que essa necessita da avaliação dos pesos, antes e após a embebição.

Em resumo, os resultados obtidos permitem sugerir o emprego do teste da capacidade de absorção

Tabela 2 - Coeficientes de correlação de Pearson entre as características tempo de cozimento (cocção), capacidade de absorção da água (absorção), percentagem de grãos normais (normais), percentagem de grãos duros (duros), volume absorvido (volume) e tempo de embebição (tempo) para duas cultivares de feijão. Santa Maria - RS, UFSM, 2003.

\begin{tabular}{|c|c|c|c|c|c|}
\hline Característica & tempo (h) & volume (\%) & duros $(\%)$ & normais $(\%)$ & absorção (\%) \\
\hline & \multicolumn{5}{|c|}{ TPS Nobre } \\
\hline Cocção (min) & $-0,6579^{*}$ & $-0,8730 *$ & $0,8953^{*}$ & $-0,8954^{*}$ & $-0,9090^{*}$ \\
\hline Absorção (\%) & $0,7637^{*}$ & $0,9582 *$ & $-0,9625^{*}$ & $0,9625^{*}$ & \\
\hline Normais $(\%)$ & $0,6740^{*}$ & $0,9388^{*}$ & $-1,0000^{*}$ & & \\
\hline Duros $(\%)$ & $-0,6740^{*}$ & $-0,9388^{*}$ & & & \\
\hline \multirow[t]{2}{*}{ Volume (\%) } & $0,8300 *$ & & & & \\
\hline & & & ... Pérola ... & & \\
\hline Cocção (min) & $-0,5861^{*}$ & $-0,8039 *$ & $0,7601^{*}$ & $-0,7601^{*}$ & $-0,7900^{*}$ \\
\hline Absorção (\%) & $0,7611^{*}$ & $0,9759 *$ & $-0,9812 *$ & $0,9812^{*}$ & \\
\hline Normais (\%) & $0,7474 *$ & $0,9631 *$ & $-1,0000^{*}$ & & \\
\hline Duros (\%) & $-0,7474^{*}$ & $-0,9631^{*}$ & & & \\
\hline Volume $(\%)$ & $0,8296^{*}$ & & & & \\
\hline
\end{tabular}

* Significativo a $1 \%$ de probabilidade de erro, pelo teste t, com 25 graus de liberdade. 
da água pelos grãos como indicativo de linhagens com características de qualidade de grãos para o cozimento, tais como cozimento rápido, alta percentagem de grãos normais e mínima percentagem de grãos duros.

\section{CONCLUSÕES}

A hidratação máxima dos grãos de feijão das cultivares TPS Nobre e Pérola ocorre as $13 \mathrm{~h} 7 \mathrm{~min}$ e as $13 \mathrm{~h} 12 \mathrm{~min}$, respectivamente, enquanto que o tempo de cozimento diminui com o aumento do tempo de permanência dos grãos em embebição até as 12h49min. A capacidade de absorção da água pelos grãos apresenta correlação negativa e significativa com o tempo de cozimento.

\section{REFERÊNCIAS BIBLIOGRÁFICAS}

BELICUAS, P.R. et al. Controle genético da capacidade de cozimento dos grãos de feijão. In: CONGRESSO BRASILEIRO DE MELHORAMENTO DE PLANTAS, 1., 2001, Goiânia, GO. Anais... Goiânia : SBMP, 2001. CD-ROOM.

BRASIL - MINISTÉRIO DA AGRICULTURA E DO ABASTECIMENTO. ANEXO IV. Requisitos mínimos para determinação do valor de cultivo e uso de feijão (Phaseolus vulgaris), para a inscrição no registro nacional de cultivaresRNC. Sl, 2001. np.

CARBONELL, S.A.M. et al. Qualidade tecnológica de grãos de genótipos de feijoeiro cultivados em diferentes ambientes. Bragantia, Campinas, v.62, n.3, p.369-379, 2003

CARNEIRO, J.D.S. et al. Potencial tecnológico dos grãos de linhagens de feijão (Phaseolus vulgaris L.). In: REUNIÃO NACIONAL DE PESQUISA DO FEIJÃO, 6., 1999, Goiânia, GO. Anais... Goiânia : Embrapa, 1999a. 880p. p.408-411.

CARNEIRO, J.D.S. et al. Qualidade tecnológica dos grãos de linhagens de feijão. In: REUNIÃO NACIONAL DE
PESQUiSA DO FEIJÃO, 6., 1999, Goiânia, GO. Anais... Goiânia : Embrapa, 1999b. 880p. p.412-415.

CEPEF. Feijão: recomendações técnicas para cultivo de feijão no Rio Grande do Sul. Erechim : São Cristóvão, 2001. 112p.

COSTA, G.R. et al. Variabilidade para absorção de água nos grãos de feijão do germoplasma da UFLA. Ciência e Agrotecnologia, Lavras, v.25, n.4, p.1017-1021, 2001.

DALLA CORTE, A. et al. Enviroment effect on grain quality in early common bean cultivars and lines. Crop Breeding and Applied Biotechnology, Londrina, v.3, n.3, p.193-202, 2003 .

GARCIA-VELA, L.A.; STANLEY, D.W. Water-holding capacity in hard-to-cook bean (P. vulgaris L.): effect of $\mathrm{pH}$ and ionic strength. Journal of Food Science, Chicago, v.54, n.4, p.1080-1081, 1989.

PLHAK, L.C. et al. Comparision of methods used to characterize water imbibition in hard-to-cook beans. Journal of Food Science, Chicago, v.54, n.3, p.326-336, 1989.

PROCTOR, J.R.; WATTS, B.M. Development of a modified Mattson bean cooker procedure basead on sensory panel cookability evaluation. Canadian Institute of Food Science and Technology Journal, Apple Hill, v.20, n.1, p.9-14, 1987.

RAMALHO, M.A.P. et al. Genética quantitativa em plantas autógamas: aplicações ao melhoramento do feijoeiro. Goiânia : UFG, 1993. 271p.

RAMOS JÚNIOR, E.U.; LEMOS, L.B. Comportamento de cultivares de feijão quanto à produtividade e qualidade dos grãos. In: CONGRESSO NACIONAL DE PESQUISA DE FEIJÃO, 7., 2002, Viçosa, MG. Anais... Viçosa : UFV, 2002. 814p. p.263-266.

RAMOS JÚNIOR, E.U. et al. Características produtivas e tecnológicas de genótipos de feijão. In: CONGRESSO NACIONAL DE PESQUISA DE FEIJÃO, 7., 2002, Viçosa, MG. Anais... Viçosa : UFV, 2002. 814p. p.267- 